services by entering the Medical Reserve Corps of the Army.

With three entirely independent publications in the field, there will be offered the full benefits of competition for both readers and writers. But it will be healthy competition between strong journals, and on a high plane. Then there remains the competition of the general medical journals. Many papers on ophthalmic subjects, written to meet the needs of the general medical profession, ought to be published in general medical journals, rather than in those read principally by the specialist. Doubtless in these general journals, a certain proportion of papers that should be read by the specialist will continue to appear. But the substance of these will be found among our abstracts, and in the Digest of the I.iterature.

On the whole, the outlook for the literature of ophthalmology among English-speaking ophthalmologists is very bright. When the present war is finished in a way to render future war unnecessary, we can look forward to an era of important progress in this literature.

E. J.

\section{REPORTING OF ACCIDENTS FROM LOCAL ANESTHETICS.}

The subjoined communication from the Committee on Therapeutic Research of the Council of Pharmacy and Chemistry of the American Medical Association is one which will especially interest the oculist. Probably the majority-certainly a large proportionof our operations are performed under the influence of a local anesthetic, especially cocain, and without doubt all of us can recall cases of untoward happening, ranging from faintness to syncope. Although the communication specially requests information regarding injections of local anesthetics, it certainly cannot mean to exclude conditions following instillations into the conjunctival sac. While the pioneer is forced to come to his conclusions on the basis of a few cases, the most accurate knowledge is obtained by the collection and coordination of facts obtained from the experiences of many workers over a long time. Certainly the use of local anesthetics in Ophthalmology has been practiced long enough to permit the statement of definite facts concerning their actions. We hope that our readers will respond to the request of the committee, and on their behalf, thank them in advance.

\section{L.}

To the Editor:- The Committee on Therapeutic Research of the Council on Pharmacy and Chemistry of the American Medical Association has undertaken a study of the accidents following the clinical use of local anesthetics, especially those following ordinary therapeutic doses. It is hoped that this study may lead to a better understanding of the cause of such accidents, and consequently to methods of avoiding them, or, at least, of treating them successfully when they occur.

It is becoming apparent that several of the local anesthetics, if not all of those in general use, are prone to cause death or symptoms of severe poisoning in a small percentage of those cases in which the dose used has been hitherto considered quite safe.

The infrequent occurrence of these accidents and their production by relatively small doses point to a peculiar hypersensitiveness on the part of those in whom the accidents occur. The dlata necessary for a study of these accidents arc at present wholly insufficient, especially since the symptoms described in most of the cases are quite different from those commonly observed in animals even after the administration of toxic, but not fatal, doses.

Such accidents are seldom reported in detail in the medical iiterature, partly because physicians and dentists fear that they may be held to blame should they report them, partly, perhaps, because they have failed to appreciate the importance of the matter from the standpoint of the protection of the public.

It is evident that a broader view should prevail, and that physicians should be informed regarding the conditions under which such accidents occur in order that they may be avoided. It is also evident that the best protec- 
tion against such unjust accusations, and the best means of preventing such accidents consist in the publication of carefully detailed records when they have occurred, with the attending circumstances. These should be reported in the medical or dental journals when possible: but when, for any reason. this seems undesirable, a conficlential report may be filed with $\mathrm{Dr}$. R, A. Hatcher, 414 East 'Twenty-sixth street, New York City, who has been appointed by the Committee to collect this information.

If desired, such reports will be considered strictly confidential so far as the name of the patient and that of the medical attendant are concerned and such information will be used solely as a means of studying the problem of toxicity of this class of agents, unless permission is given to use the name.

All available facts, both public and private, should be included in these reports, but the following data are especially to be desired in those cases in which more detailed reports cannot be made:

The age, sex, and general history of the patient should be given in as great detail as possible. The state of the nervous system appears to be of especial importance. The dosage employed slould be stated as accurately as possible; also the concentration of the solution employed, the site of the injection (whether intramuscular, perineural or strictly subcutaneous), and whether applied to the mouth, nose, or other part of the body. The possibility of an injection having been made into a small vein cluring intramuscular injection or into the gums should be considered. In such casces the action begins almost at once, that is, within a few seconds.

The previous condition of the heart and respiration should be reported if possible; and, of course, the effects of the drug on the lieart and respiration, ats well as the duration of the symptoms, should be recurded. If antidotes are employed, their nature and dosage should be stated, together with the character and time of appearance of the effects induced by the antidotes. It is important to state whether antidotes were aclministered orally, or by subcutaneous, intramuscular or intravenous injection, and the concentration in which such antidotes were used.

While such detailed information, together with any other available data, are desirable, it is not to be understood that the inability to supply such details should prevent the publication of reports of poisoning, however meager the data, so long as accuracy is observed.

The commitlee urges on all anesthetists, surgeons, physicians and dentists the making of such reports as a public duty; it asks that they read this appeal with especial attention to the character of observations desired.

Toralod Soldlman, Chairman.

R. A. HATCIER, Special Referee.

\section{BOOK NOTICES.}

ANATOMICAL NAMES, Especially the Basle Nomina Anatomica (BNA) - Albert Chauncey Eycleshymer, B. S., Ph. D., M. D., asisisted by Daniel Martin Schoemaker, B, S., M. D., with Biographical Sketches, by Roy Lee Moodie, A. B., Ph. D., Octavo 764 pages, illustrated by numerous wood engravings and by two fullpage plates in red and black. New York City. William Wood and Company. \$4.50 net.

This is almost entirely a book of reference for editors, atthors, teachers, and for those pliysicians who aspire to purity of technical language. The author has followed the exhatustive six years' compilation of the Basle Nomina Anatromica, completed in 1894; and later published in book form in an arrangement rather difficult of orientation, as the terms were only given according to systems. So in order to facilitate the work, all the terms are arranged alphabetically with cross references to each, citing the page and serial number of the terms in their systematic positions, supplemented by 20,000 symonyms. This is the piece 